\title{
Tradutores-interpretes de línguas de sinais: funções e atuação nas redes de ensinos ${ }^{1}$
}

\author{
Adriane Melo de Castro Menezes* \\ Cristina Broglia Feitosa de Lacerda**
}

\section{Resumo}

Este artigo discute algumas condições funcionais de Tradutores-Intérpretes de Língua de Sinais (TILS) que atuam no processo de escolarização de alunos surdos matriculados em escolas da rede regular de ensino. Empreendemos discussóes sobre aspectos como vinculação funcional e salários, tentando perceber como estes sujeitos se sentem em seus lugares, e como estas questóes afetam seu cotidiano. Fundamentado na teoria enunciativo-discursiva de Mikhail Bakhtin, este estudo teve como base principal da construção dos dados entrevistas presenciais, e complementarmente, um perfil com dados sobre formação, vinculação e experiência profissional. Além de anotaçôes de elementos contextuais, relevantes para a compreensão dos sujeitos e seus discursos. Participaram 27 TILS, de treze municípios distribuídos em oito estados brasileiros. Quanto aos resultados, foi marcante que para os TILS não se trata apenas de nomenclaturas de e para vínculos funcionais. Estas questôes têm desdobramentos, que podem incidir nas expectativas de atuação e representaçôes sociais atreladas. Os dados também mostram um movimento social diverso para o atendimento das políticas públicas de educaçấo e inclusão em vigor que, a depender de cada situação específica, podem comprometer, sobremaneira, a forma como estes TILS são vistos e sua integração-participação no coletivo institucional.

Palavras-chave: Tradutores-intérpretes de Língua de Sinais; Escolarização de surdos; Condição funcional.

* Professora Doutora da Universidade Federal de Roraima, Roraima, Brasil.

** Professora Doutora da Universidade Federal de São Carlos, São Carlos, São Paulo, Brasil. 


\section{Translators-Interpreters of sign languages: functions and performance in educational networks}

\section{Abstract}

This article discusses some functional conditions criterion of Sign Language Translators- Interpreters (TILS), that act in the process of deaf student education enrolled in brazilian schools at the regular education system. We undertake discussions on aspects such as functional linking and wages, trying to see how these subjects feel themselves in their places, and how they are affected by it in their daily lives. Grounded on the enunciation-discourse theory of Mikhail Bakhtin, this study utilized employed face-to-face interviews as a main base on data construction, and in addition, one profile with training data, bonding and professional experience. Also taking notes of contextual elements, were relevant to the subjects' understanding and their speeches. Altogether 27 TILS participated from thirteen municipalities among eight Brazilian states. As results, it was outstanding that TILs are not just about nomenclatures and functional linking. Such developments, may affect the performance expectations and linked social representations. The data also demonstrate a diverse social movement to meet the existing education and inclusion public policies, depending on each specific situation, may compromise, greatly, how these TILS are seen and their integration -participation in the institutional as a whole.

Keywords: Sign language translators-interpreters; Deaf education; Functional status.

Fugindo de extremismos e pessimismos que, em geral, nos imobilizam, consideramos importante reconhecer que, mesmo embebidos em contradiçôes, temos conquistado avanços significativos no campo das políticas públicas de educação e inclusão, como estágio fundamental à transformação das condições político-sociais, principalmente quando relacionadas à garantia de direitos de pessoas com deficiência e de minorias étnicas e/ou identitárias. Avanços legais, como, por exemplo, a Lei ${ }^{\circ}$ 10.098/00 (BRASIL, 2000), que dispóe sobre acessibilidade, o Decreto ${ }^{\circ}$. 5.626/05, que regulamenta a Lei n. ${ }^{\circ} 10.436 / 02^{2}$ (BRASIL, 2002), e, com foco direto na realidade dos nossos sujeitos, a Lei $n^{\circ} 12.319 / 10$ (BRASIL, 2010), que regulamenta a profissão de Tradutor-Intérprete da Língua Brasileira de Sinais.

No âmbito acadêmico, observamos que os estudos e pesquisas relacionados às temáticas da inclusão educacional de alunos surdos são crescentes, e estão em franca expansão, tanto em número, quanto em direcionamentos e áreas de conhecimento envolvidas. Isto tem trazido ganhos bastante significativos, pois coloca à disposição múltiplos olhares e possibilidades de compreensão.

Mesmo com focos, muitas vezes similares ou bem diferenciados, vimos que emergem convergências, sendo uma delas o reconhecimento como condição sine qua non ao atendimento escolar destes alunos, que as escolas se estruturem e ofereçam uma política linguística diferenciada, conectada efetivamente com o indivíduo surdo 
de maneira alteritária e não autoritária. E pensar em projetos educacionais inclusivos bilíngues para surdos implica no reconhecimento do direito que eles têm, como pessoas que usam uma língua diferente da língua majoritária, de serem educados na sua língua, sem limitar-se a proposições puramente técnico-pedagógicas, mas sociolinguisticamente justificadas e politicamente responsivas. Neste sentido, Skliar afirma que:

A educação não é politicamente "opaca" nem neutra em seus valores e, por isso, não resulta em uma tarefa simples a compreensão do papel da escola em uma sociedade dividida e fragmentada racial, social, étnica, linguística e sexualmente. A escola moderna contribui no dia a dia para esta divisão, através de quatro estratégias fundamentais: a razão instrumental - todo conhecimento deve ter uma finalidade e uma utilidade -, o controle burocrático, a cibernética das subjetividades - todas as crianças e todos os professores devem se subordinar à prática dos computadores - e a lógica binária e perversa da inclusão/ exclusão - onde quotidianamente se mudam as fronteiras e o significado do "pertencer ou não pertencer". [...] [Neste contexto, a] educação bilíngue para surdos, como qualquer projeto/proposta educacional, náo pode ser neutra nem opaca. Porém, falta a consistência política para entender a educação dos surdos como uma prática de direitos humanos [...]; a coerência ideológica para discutir as assimetrias do poder e do saber entre surdos e ouvintes; a análise da natureza epistemológica das representaçôes colonialistas sobre a surdez e os surdos (2009, p.08-09).

Ressaltamos que o reconhecimento político da surdez precisa ser discutido e compreendido, tanto por seu valor direto (a causa), quanto no seu importante papel de oposição aos discursos e às práticas hegemônicas. Estas têm buscado restringir os debates sobre projetos inclusivos bilíngues e transformá-los em metodologia, sem o reconhecimento de sua própria historicidade e matizes sociais e políticas. Tais questôes remontam ao que tratam Miotello e Pimenta, quando apontam que

A afirmação da identidade e a marcação da diferença passam por relaçóes de poder, tais como incluir/excluir, demarcar tentativas que buscam homogeneizar a identidade como se a mesma fosse uma espécie de essência natural, - nascida de um tempo vertical, vazio, homogêneo, constituída ao redor de binarismo (masculino/ feminino, branco/negro, heterossexual/homossexual) -, não deixam de serem estratégias de poder que tentam fixar normas, parâmetros e modelos para as identidades (2010, p.289).

Questôes organizacionais e técnico-pedagógicas, mesmo referidas em segunda instância, não são menos importantes, e merecem consideraçóes próprias, que reconhecemos como fundamentais, como: é inescapável à organização de projetos de educação inclusiva bilíngues para surdos, uma reestruturação do espaço escolar. Sobre isso, destacamos, principalmente, a escola como espaço discursivo, de produçáo e circulação de discursos que incidem nos modos de relação e constituição de cada um de seus integrantes - em maior ou menor grau de impacto, reconhecimento e valorização etc. 
Os modos de constituição de sentidos e do próprio conhecimento não se sustentam apenas em estratégias e/ou metodologias, mas sim pelas formas pelas quais a palavra circula. É preciso pensar na instituição-escola como um lugar-tempo, no qual cada um, na sua singularidade, ocupa um lugar próprio e determinante na forma como significa e de como é significado pelos demais sujeitos com os quais interage e se relaciona. Segundo Bakhtin e Volochinov, "qualquer que seja o aspecto da expressão-enunciação considerado, ele será determinado pelas condiçóes reais da enunciação em questão, isto é, antes de tudo pela situaçáo social mais imediata" (2010, p.116), o que torna ainda mais relevante pensar sobre o lugar do/para os surdos nas escolas com projetos de inclusão bilíngues, pois isto implicará diretamente nos discursos construídos.

Desta forma, e sem desmerecer o valor de estratégias e metodologias, destacamos, neste segundo plano de argumentação, que a escola é um território de negociaçóes constante sobre os sentidos dos lugares simbólicos que cada um dos sujeitos irá ocupar nas relaçôes, o lugar social de professores, alunos ouvintes, alunos surdos, intérpretes de língua de sinais, educadores surdos, considerando a complexidade de cada papel e demandas. Segundo Lacerda (2000), quando se fala em educação para surdos, o processo de interlocução não pode se restringir às atividades acadêmicas, a serem repassadas pelo intérprete.

Estes profissionais têm potência para dispor aos alunos surdos e às instituiçóes, mas precisam de espaço para materializar isto - não estamos falando de um espaço, donde ficarão nas salas de aula para realizarem o ato tradutório em si, estamos falando de um lugar próprio para Ser, para se constituírem TILS, profissionais que fazem parte de um projeto-processo de inclusáo educacional para alunos surdos.

Neste contexto, é fundante que a Língua Brasileira de Sinais (Libras) circule, sem limitaçóes, no todo da escola, que não fique restrita aos alunos surdos e intérpretes, que haja o reconhecimento da Libras como fator essencial ao desenvolvimento e à construção de pertença para os surdos, o que denota clara predisposição da escola a acolher estes Outros, reconhecendo neles sua diferença sociolinguística e singularidades. Além do que isso é determinante para o planejamento e a vivência de um trabalho responsável diante de todos os envolvidos em projetos de inclusão educacional, visto que a consciência e o compromisso em relação a estes aspectos nos tornam mais aptos ao ato responsivo, em projetos para a escolarização de surdos, mas também de tantos outros.

Mas não temos como aprofundar o olhar para as questôes dos TILS - suas funçóes e práticas - nas escolas, sem sair, olhar de e para fora. Dentro de uma perspectiva mais macrossocial, que situa as escolas nos complexos sistemas de ensino e as coloca em relação com as políticas públicas em vigência, ver o TILS, neste cenário, nos levou a pensar em algumas questôes práticas e que têm máxima incidência nos problemas enfrentados por eles mesmos no cenário atual da educação inclusiva e atendimento de alunos surdos nas redes regulares de ensino. 


\section{Foco e caminhos da investigação}

Dentre as possibilidades de recorte da pesquisa integral, apresentada na forma de tese de doutoramento, escolhemos olhar neste trabalho para questóes referentes aos cargos e vínculos, ou melhor, aos diversos perfis de enquadramento funcional de TILS, na busca de perceber como estes sujeitos se sentem em seus "lugares"3, e como isto repercute no seu cotidiano. Para dar mais visibilidade aos aspectos aos quais nos referimos, fizemos uma síntese dos dados coletados, que demonstra as diferentes situaçôes funcionais a que estão vinculados profissionalmente os sujeitos. Mas antes de mostrar as realidades encontradas, vamos falar um pouco sobre os sujeitos, como os encontramos, pois o processo da pesquisa é parte constitutiva dos dados.

Fundamentados teoricamente na teoria enunciativo-discursiva da linguagem de Mikhail Bakhtin, nossos procedimentos metodológicos (construção dos dados, organizaçấo e discussóes apresentadas) tem como premissa a compreensão de que todo sujeito é histórico, marcado por uma cultura, "[...] como criadores de ideias e consciência que, ao produzirem e reproduzirem a realidade social, são ao mesmo tempo produzidos e reproduzidos por ela" (FREITAS, 2002, p.22), além da preocupação com o fato de que nosso "objeto" nos desafiava a construção de um traçado metodológico que náo comprometesse nem de sua amplitude, nem de sua humanidade.

Em relação aos sujeitos e procedimentos, escolhemos nossos participantes a partir do seguinte perfil - atuantes em séries do Ensino Fundamental II ( $6^{\circ}$ ao $9^{\circ}$ ano), em escolas das redes públicas, e que acompanhassem, de modo contínuo, alunos surdos durante o ano letivo. Conseguimos reunir um grupo com 27 TILS, em 8 (oito) estados brasileiros, o que abrangeu as cinco regióes brasileiras (Rio Branco/AC, Fortaleza e Maracanaú/CE, Brasília/DF, Campo Grande, Inocência e Chapada do Sul/MS, Campinas e Santa Cruz das Palmeiras/SP, Rio de Janeiro/RJ, Florianópolis e Itajaí/ $\mathrm{SC}$ e Pelotas/RS $\left.{ }^{4}\right)$. Os dados foram construídos com base em entrevistas presenciais (gravadas e transcritas), que foram planejadas via contato virtual (e-mails), exclusivamente para a pesquisa, além de anotaçôes sobre questôes contextuais, que poderiam contribuir para a compreensão dos sujeitos e seus discursos. As entrevistas não tinham um roteiro fechado, tínhamos temas que eram colocados em diálogo e daí eles falavam livremente acerca de questóes como suas práticas e contextos profissionais. Para compressáo dos dados estabelecemos como centralidade conceitos como; discurso, sujeito, dialogia e ideologia, que nortearam nossa percepção a cerca dos sentidos e significados atribuídos pelos TILS às suas realidades materiais e universos relacionais, bem como o modo como sujeitos compreendem seu papel e responsabilidades, como olham para o lugar ocupado por eles nos cenários de desenvolvimento da escolarização de alunos surdos.

\section{Nosso olhar sobre as realidades e seus reflexos na cotidianidade dos TILS}

Vemos, na figura 1 (a seguir), que apenas $29,6 \%$ são concursados, o que lhes dá, a priori, seguridade, enquanto $48,1 \%$ encontram-se com vínculo temporário - o que, dependendo de cada estado/município e das práticas e políticas públicas, pode 
significar maior ou menor instabilidade de vínculos -, e 22,2\% estão nos campos de trabalho, vinculados a empresas contratadas pelas secretarias de educação, numa relação de prestadores de serviços para as escolas.

Figura 1 - Distribuição dos sujeitos em relação a situação funcional

\begin{tabular}{|l|r|r|}
\hline \multicolumn{3}{|c|}{ Situaçäo Funcional } \\
\hline Taxa de resposta: $100,0 \%$ \\
\hline Concursados & Qt. & $\%$ cit. \\
\hline Contratos Temporários & 8 & $29,6 \%$ \\
\hline Emp Terceirizada SEMED & 13 & $48,1 \%$ \\
\hline Total & 27 & $22,2 \%$ \\
\hline
\end{tabular}

Fonte: Entrevistas individuais com os TILS e questionário com perfil dos participantes

Nossa leitura destes dados é que existem aspectos de diversas naturezas a orbitar em torno desta questáo. Eles mostram um movimento social diante das novas demandas em curso, para o atendimento das políticas públicas de educaçáa em vigor - que revelam que em alguns lugares os cargos foram criados, enquanto, em outros, as vinculaçôes se dáo de outros modos, como, por exemplo, por meio de contratos dos sistemas municipais com empresas terceirizadas, sem definir um vínculo mais direto com estes profissionais.

Neste caso em particular, como os TILS, a depender dos tipos de contratos, são direcionados aos locais onde deverão trabalhar, e a avaliação do processo é feita a margem da gestấo escolar (leia-se gestáo como a equipe institucional - desde os gestores administrativos aos técnico-pedagógicos), isto pode vir a dificultar a situação dos TILS frente à comunidade escolar, intervindo no processo de estabelecimento de vínculos. Esta situação específica pode comprometer, sobremaneira, a forma como estes TILS são vistos e sua integração-participação no coletivo institucional.

Não se trata da forma de atuação em si, já que aparentemente todos atuam nas escolas com funçốes semelhantes - estấo em questionamento os desdobramentos destas formas de contrato, ou seja, dos sentimentos e sensaçóes de insegurança e instabilidade quanto à permanência na escola e continuidade no trabalho desenvolvido. Insegurança no que se refere ao acompanhamento e suporte para o trabalho, afinal, em alguns casos, quem acompanha não avalia e nem decide por sua lotaçáo - reflexos destes vínculos no comportamento, sentimentos e significaçóes em jogo.

E, sem querer pecar por omissão, é preciso problematizar que não se trata mais de discutir onde esta educaçáo deve ocorrer - se nas escolas especiais ou regulares, visto que acreditamos na possibilidade de que cada uma pode desenvolver bons trabalhos e que cabe às famílias o direito de escolher sobre esta questáo. Ainda que isto seja de suma importância, o principal a ser considerado é: como ela será ofertada?; quais as mudanças sistêmicas necessárias, as indispensáveis e as urgentes, para que se estabeleçam planos de curto, médio e longo prazo e metas a serem alcançadas? 
Tabela 1 - Sobre a situação funcional e vinculação dos sujeitos

\begin{tabular}{|c|c|c|c|}
\hline Cidade que Atua & Cargos e Vínculos & Situaçáo Funcional & $\begin{array}{l}\text { Salário - com base no } \\
\text { salário mínimo nacional }\end{array}$ \\
\hline Fortaleza - CE (1) & Professor Estagiário ${ }^{5}$ & Contrato Temporário & 1 Salário Mínimo \\
\hline Pelotas - RS (3) & Intérprete de Libras & Concursados & 1 Salário Mínimo \\
\hline Campinas - SP (2) & TILS & Contrato Temporário & de 1 a 3 salários mínimos \\
\hline $\begin{array}{c}\text { Florianópolis - SC } \\
\text { (1) }\end{array}$ & $\begin{array}{c}\text { Auxiliar de Ensino de } \\
\text { Libras }\end{array}$ & Concursado & de 1 a 3 salários mínimos \\
\hline $\begin{array}{c}\text { Florianópolis - SC } \\
(1)\end{array}$ & $\begin{array}{c}\text { Auxiliar de Ensino de } \\
\text { Libras }\end{array}$ & Contrato Temporário & de 1 a 3 salários mínimos \\
\hline Fortaleza - CE (1) & Intérprete de Libras & $\begin{array}{c}\text { Prestador de Serviço para } \\
\text { Empresa Terceirizada } \\
\text { pela SEMED }\end{array}$ & de 1 a 3 salários mínimos \\
\hline Iatajaí - SC (1) & Intérprete de Libras & Contrato Temporário & de 1 a 3 salários mínimos \\
\hline Iatajaí - SC (1) & Professor Intérprete & Contrato Temporário & de 1 a 3 salários mínimos \\
\hline Maracanaú - CE (1) & Intérprete de Libras $^{6}$ & $\begin{array}{c}\text { Prestador de Serviço para } \\
\text { Empresa Terceirizada } \\
\text { pela SEMED }\end{array}$ & de 1 a 3 salários mínimos \\
\hline Rio Branco - AC (1) & Professor Intérprete & Contrato Temporário & de 1 a 3 salários mínimos \\
\hline $\begin{array}{c}\text { Rio de Janeiro - RJ } \\
(3)\end{array}$ & TILS & $\begin{array}{c}\text { Prestador de Serviço para } \\
\text { Empresa Terceirizada } \\
\text { pela SEMED }\end{array}$ & de 1 a 3 salários mínimos \\
\hline $\begin{array}{c}\text { Chapadão do Sul - } \\
\text { MS (1) }\end{array}$ & TILS & Contrato Temporário & de 3 a 5 salários mínimos \\
\hline Inocência - MS (1) & Professora & Contrato Temporário & de 3 a 5 salários mínimos \\
\hline Maracanaú - CE (1) & Intérprete de Libras & $\begin{array}{c}\text { Prestador de Serviço para } \\
\text { Empresa Terceirizada } \\
\text { pela SEMED }\end{array}$ & de 3 a 5 salários mínimos \\
\hline Rio Branco - AC (2) & Professor Intérprete & Contrato Temporário & de 3 a 5 salários mínimos \\
\hline $\begin{array}{c}\text { Campo Grande - MS } \\
(2)\end{array}$ & Professor(a) & Contrato Temporário & de 5 a 8 salários mínimos \\
\hline $\begin{array}{c}\text { Santa Cruz das } \\
\text { Palmeiras - SP (1) }\end{array}$ & $\begin{array}{c}\text { Professora Intérprete de } \\
\text { Libras }\end{array}$ & Concursada & de 5 a 8 salários mínimos \\
\hline Brasília - DF (3) & $\begin{array}{c}\text { Professores de } \\
\text { Licenciaturas Específicas }\end{array}$ & Concursadas & $\begin{array}{c}\text { acima de } 8 \text { salários } \\
\text { mínimos }\end{array}$ \\
\hline
\end{tabular}

Fonte: Entrevistas individuais com os TILS e questionário com perfil dos participantes da pesquisa

Um aspecto bastante prático, o que não quer dizer simples, do que acabamos de abordar é a questão dos modos como os TILS estão sendo inseridos nestas estruturas sistêmicas - são concursados, estão vinculados de que forma, quais os cargos destinados a eles? Daí cabem algumas consideraçôes: primeiro, embora pareçam questóes muito amplas, ou até mesmo abstratas, ao se tratar de um estudo que abrangeu oito 
estados, quisemos observar questóes como a média salarial dos sujeitos, por exemplo, como isso foi trazido concretamente por eles, quais as relaçôes possíveis.

De saída, observarmos nos dados que as informaçôes não dariam base para se pensar nos salários de ou para TILS, posto que as referências mantinham correlação com os tipos de vínculo. Para dar a visibilidade possível à questão, na tabela 1 , fizemos o demonstrativo com base no salário mínimo nacional, no qual se vê que, nas categorias encontradas ( $1 \mathrm{SM}^{7}$; de 1 a $3 \mathrm{SM}$; de 3 a 5 SM; de 5 a 8 SM; e acima de $8 \mathrm{SM}$ ), encontram-se misturados sujeitos com todos os tipos de situaçáo funcional (Concursado; Contrato Temporário; e contratados via Empresa Terceirizada pela SEMED).

No que se refere ao que pensam e como veem as questôes de salário, os TILS, de modo mais ou menos intenso, em geral se colocam como insatisfeitos - quer no reconhecimento de que é desproporcional às demandas da função, quer porque estejam no piso mínimo admitido por lei -, ficando em situaçáo menos polêmica os Tradutores-Intérpretes que são concursados como professores, visto que, embora desempenhem a função de TILS, são remunerados pelo piso salarial estabelecido para a função docente e, ainda, usufruem de todos os benefícios oferecidos a esta categoria de trabalhadores, como podemos observar nas seguintes falas:

JÚLIA $(A C)$ - contrato temporário: o salário não é um dos melhores/ infelizmente a gente não é valorizado como poderia/ algumas pessoas são/ são medíocres em dizer que interprete só aproveita do surdo para ganhar dinheiro/ que a gente já ouviu muitas vezes/ algumas pessoas dizem que mexer as mãozinhas é muito fácil

CLÓVIS (MS) - contrato temporário: o salário não é tão bom/ mas do momento em que eu aceitei estar ali/ vamos lutar para melhorar/ mas vou fazer bem o que eu faço/[...] na verdade você ta trabalhando dentro/ EM sala de aula/ vinte e cinco horas e o professor regente faz vinte horas sendo que normalmente oito ele está em sala, doze ele sai, que dizer/ ele tem folg/ o intérprete não/ trabalha cinco dias na semana o tempo todo com o aluno e isso além de ser cansativo isso/ enfraquece o trabalho também/

MÁRIO (RJ) - prestador de serviço para empresa terceirizada: eu vou falar aqui/ está gravando? [tá] o salário de intérprete hoje sabe o que que isso aqui/sabe que esse valor descartável (sinaliza - "sem valor") sinceramente / é altamente insatisfatório/ eu faço mais as$\mathrm{sim} /$ por enquanto/ agora porque eu gosto do surdo/ porque eu prefiro trabalhar/ isso aqui como social porque é social/ [...]/ porque para mim é mais gratificante do que trabalhar assim porque o salário é um desastre

MOYRA (RS) - concursada como Intérprete de Libras: [...] nós ganhamos o salário mínimo, mas na verdade o salário base é menor que o salário mínimo/ a gente só ganha o salário mínimo em funçấo de que é contra lei/ né?/ ilegal ganha menos que o salário mínimo/ eu não me lembro o salário base mas ele há um tempo era por volta de duzentos e oitenta e alguma coisa e ai tinha aquela complementação para chega ao mínimo/ então era o mínimo 
por obrigação da / né? [você colocou todos os professores/ vocês entram na rede/ a partir de concursos/ eh que são gerais né?/ e daí vão se encaminhando ou não para uma atuação na área da educação especial. Isso financeiramente tem algum impacto? Vocês recebem alguma diferença porque atuam na educação especial?]

THAÍS (DF) - concursada como professora: Tem/ um impacto. Um impacto é mínimo Financeiro. Eu acho que o impacto/ existe um impacto financeiro, mas é muito pouco está uns cento e cinquenta reais/ e vão diminuir (RISOS)/ porque a ideia com a inclusão é (uma ideia) até que/ é complicado a gente/ Discutir / mas a ideia é como há uma inclusão todos os professores atendem/ mas o único (...) que tem necessidades educativas/ na verdade se a gente for pensar bem/ todo aluno tem uma necessidade educativa especial (...) é aí como todos os professores fazem esse atendimento/ todos teriam que receber a gratificação.

Outro ponto: não se trata apenas de nomenclatura de e para vínculo, este ponto tem desdobramentos, que podem incidir nas expectativas de atuação e representaçôes sociais atreladas. Pois entendemos que, mesmo ficando ajustadas as funçôes, socialmente, quando um TILS é apresentado às instituiçóes como PROFESSOR-INTÉRPRETE, a nomenclatura pode gerar expectativas adicionais às suas funções, o que acarreta, no mínimo, uma preocupação ou tarefa a mais para eles - esclarecer que não são responsáveis pelo ensino ou que suas funçôes são diferentes das dos professores regentes.

[Danúsia, você na rede/ pelo teu contrato é professora-intérprete, como você vê isso?] DANÚSIA (AC): Assim né? professor-intérprete//... Entre aspas porque a gente não está lá ensinando/ a gente está intermediando/ quem está ensinando lá é o professor né?/ Eu acho que a nomenclatura ideal seri// se tivesse né?/ se a gente fosse reconhecido mesmo como profissional/ não precisaria do professor/ só intérprete mesmo/ profissional intérprete. Eu acho que ficaria melhor/ eu acho que ficaria mais correto.

Este fato não soa surpreendente, ao considerarmos que a orientação e o encaminhamento de alunos surdos para as redes regulares de ensino, o nascimento desta nova categoria profissional (os TILS), seu reconhecimento legal, é tudo muito novo, mesmo que o débito social com a população surda não o seja.

Isto pode ter várias implicaçôes diretas, como: dificultar a visibilidade de aspectos importantes relacionados à formação, profissionalização e remuneração - o que, por decorrência, pode comprometer bastante o fortalecimento destes enquanto categoria de trabalho, bem como a conquista de espaços de discussão e atuação próprios, nos quais sintam suas problemáticas contempladas, em que discutam e busquem, também coletivamente, por suas respostas.

No universo dos sujeitos da pesquisa, observamos, entáo (tabela 5), que oito sujeitos são concursados, mas, como podemos observar, também, apenas os TILS de Pelotas são concursados dentro da especificidade de suas funçôes. Os demais sujeitos concursados - que atuam em Florianópolis, Santa Cruz das Palmeiras e Brasília - atu- 
am como TILS, mas são contratados com outros nomes - em uma espécie de desvio funcional, pois seus vínculos não correspondem à função que realmente exercem - TILS. O mesmo se observa no que tange as médias salariais, que não atendem a padróes ou categorias de proporcionalidade ligadas à situação funcional dos mesmos. Isto indica que as redes de ensino estão desafiadas a encontrar soluçôes, meios de garantir a presença dos TILS nas escolas com alunos surdos matriculados e estão fazendo isto, de acordo com sua realidade política e social, considerando que as relaçóes de poder tencionam isto de modo plural.

Adentrando às questôes de forma de contratação e valorização do profissional e sobre o lugar que ele ocupa no quadro funcional, trouxemos algumas falas dos sujeitos, sobre como se sentem e agem diante de questóes burocráticas, como as vinculações, e o cotidiano escolar.

MIGUEL (SC): assim vamos pensar na parte burocrática/ primeiro quando você presta concurso lá né?/ quando prestei o concurso tinha o edital e ele descreve minha função ali naquela parte ali a função do auxiliar de ensino de Libras é essa e essa e essa naquela descrição ali ele diz o que é que é o auxiliar de ensino de Libras é o cara que mediador da informação' vai interpretar em sala de aula ou nos diversos espaços dentro da escola nos espaços educativos da escola a comunicação e tradução e interpretação e também aí que entra, também que vai embasar o tal de auxiliar de ensino' o auxiliar de ensino é o cara que se o aluno para quem ele interpreta faltou hoje e eu estou de bobeira vamos dizer assim né?"/ de folga / eu estou livre aqui eu estou de folga aí de repente o professor de geografia náo veio quem vai substituir o cara ali” ele tem cinco aulas hoje' aí vão pegar o auxiliar de ensino de Libras vai lá para sala de aula onde viria o de geografia seja lá qual for a disciplina e você vai lá e vai ocupar os tempos dele.

SÔNIA (SC): eu já falei para direção não/ não assumo sala/ não substituo professor eu estou ali para atuar com os cinco alunos se faltar professor a sala vai sair da sala eu saio também' fico na sala dos professores/ muitos diretores não aceitam' trabalhei numa escola que foi excelente assim a professora faltava/ uma vez me pediram e eu fiz porque eu realmente gostava muito daquela professora' da escola toda não vou me negar também a ajudar um dia que a professora tinha que ir no médico' nunca faltava' então eu ajudei ela fiquei naquele dia com os alunos' passei um videozinho para os alunos/ foi super tranquilo mas a escola sabia que não era a minha responsabilidade eles me pediam em último caso se náo tivesse ninguém do administrativo para assumir mais ninguém mesmo me pediam isso' mas aquela vez tudo vez depois para aceitar outras vezes é um pouco complicado purismo?? Para não ser contaminado com outro fazer... ou porque a escola folga... mas dá pra fazer quando gosta da escola e da professora... se você me trata bem posso te ajudar... há tensão ai e coisas muito pouco discutidas...

Vimos estas questóes contratuais como algo que pode se configurar, tanto positivamente, visto que, ao se pensar (e ser pensado), ao ser concebido, também, como auxiliar de ensino para o aluno surdo, pode corroborar com as demandas de forma- 
ção para que estes profissionais tenham recursos para atuar nas escolas, reconhecendo sua funçẫo como algo que não se limita à tradução (o que já é aspecto requerido, naturalmente, quando os TILS atuam em espaços escolares), quanto negativamente, quando as instituiçôes se utilizam da burocracia e da falta de minúcias, presentes, muitas vezes, nos atos normativos dos municípios, para, com isso, imporem aos TILS que assumam responsabilidades de ensino das turmas (como um todo), como se fossem professores substitutos - função para a qual não teriam formação específica ${ }^{8}$.

Isto nos remete à necessidade de reflexão, tanto sobre os editais (que devem ser bastante atentos à formação dos TILS), quanto sobre as situaçôes em que os TILS podem ser solicitados e devem colaborar nas diversas demandas escolares (considerando que a escola não pode parar e que os problemas com falta de professores é frequente, principalmente nas redes públicas de ensino), desde que isto não o coloque fora da sua funçáo real - como, por exemplo, deixar de atender aos alunos surdos com quem trabalham para assumir outras turmas, pois isto os tira da função e prejudica diretamente estes alunos.

\section{Reflexões e inconclusividades}

Ao discutirmos os aspectos relativos às escolas regulares, como contextos de atuação profissional dos TILS, bem como as condiçóes concretas nas quais estes sujeitos atuam, tivemos como mote compreender a materialidade, também, no que se refere aos lugares destinados a cada um destes personagens (incluindo alunos surdos e professores) no contexto escolar. E, além disso, refletir acerca da necessidade de implementação de projetos educacionais inclusivos na perspectiva bilíngue para surdos, como condicionante a inclusão desses alunos nas escolas das redes regulares de ensino e para a atuação dos sujeitos.

Abordar esta questáo é importante sob diversos aspectos - tanto para a compreensão de que estes alunos precisam desfrutar de condiçôes favoráveis ao seu desenvolvimento, quanto para visão crítica de que isto é determinante para que os TILS cumpram seu papel e contribuam, tanto quanto possível, com este objetivo.

Esta discussão não é importante, apenas, por consolidar o que já tem sido posto - que a inclusáo escolar não pode acontecer apenas com a presença dos TILS, mas, principalmente, aprofundar nossa percepção sobre o que ocorre e como se sentem estes sujeitos ao se virem sozinhos diante desta responsabilidade.

\section{Referências}

BAKHTIN, M.; VOLOCHINOV, V. N. Marxismo e filosofia da linguagem. Tradução de Michel Lahud e Yara Frateschi Vieira. 14. ed. São Paulo: Hucitec, 2010.

BRASIL. Lei $\mathbf{n}^{\circ} \mathbf{1 2 . 3 1 9}$, de $1^{\circ}$ de setembro de 2010. Regulamenta a profissão de Tradutor e Intérprete de Língua Brasileira de Sinais. Diário Oficial da República Federativa do Brasil. Brasília, 02 set. 2010.

. Decreto n. 5.626, de 22 de dezembro de 2005. Regulamenta a lei de acessibilidade, $n^{\circ} 10.098 / 2000$ e a lei de libras, $\mathrm{n}^{\circ}$ 10.426. Diário Oficial da República Federativa do Brasil. Brasília, 22 dez. 2005.

. Lei $\mathbf{n}^{\circ} \mathbf{1 0 . 4 3 6}$, de 24 de abril de 2002. Dispóe sobre a Língua Brasileira de Sinais. Diário Oficial da República Federativa do Brasil. Brasília, 24 abr. 2002.

Lei $\mathbf{n}^{\circ} \mathbf{1 0 . 0 9 8}$, de 10 de dezembro de 2000. Dispóe sobre a Lei de Acessibilidade. Diário Oficial da República Federativa do Brasil. Brasília, 19 dez. 2000. 
FREITAS, M. T. A. A abordagem sócio-histórica como orientadora da pesquisa qualitativa. Cad. Pesqui., São Paulo, n. 116, p. 21-39, 2002. Disponível em: <http://www.scielo.br/scielo.php?script=sci_arttext\&pi$\mathrm{d}=$ S0100-15742002000200002\&lng=en\&nrm=iso>. Acesso em: 29 mar. 2012.

LACERDA, C. B. F. O intérprete de língua de sinais no contexto de uma sala de aula de alunos ouvintes: problematizando a questáo. In: LACERDA, C. B. F.; GÖES, M. C. R. (Orgs) Surdez: Processos Educativos e Subjetividade. São Paulo: Editora Lovise, 2000, p.51 - 84.

MIOTELLO, V.; PIMENTA, D. S. Falando de identidade pelo lado do avesso: a alteridade como eixo. In: Grupo de Estudos dos Gêneros do discurso - GEGe. (Org.). Pensares Bakhtinianos - escritos impertinentes. 1. ed. São Carlos/SP: Pedro \& João Editores, 2010, p.285 - 299.

SKLIAR, C. Atualidade na Educação Bilíngüe para Surdos - Interfaces entre pedagogia e línguística. In SKLIAR, C. A localização política da Educação bilíngüe para surdos. Porto Alegre-RS. Editora Mediação, 2009.

\section{Notas}

${ }^{1}$ Este trabalho faz parte de uma pesquisa de doutorado. Neste texto são apresentados dados que discutem as condiçóes funcionais e suas repercussóes no pensar sobre a profissáo e no cotidiano profissional dos sujeitos participantes da pesquisa.

${ }^{2}$ Lei n. ${ }^{\circ} 10.436 / 02$ oficializa a Língua Brasileira de Sinais (Libras) como meio legal de comunicação e expressão da comunidade surda brasileira e designa que os membros desta comunidade deverão ser respeitados e atendidos em suas demandas sociais amplas, respeitando sua diferença linguística.

${ }^{3}$ Lugar no sentido de enquadramento funcional.

${ }^{4}$ Esta pesquisa foi realizada sem bolsas ou qualquer recurso financeiro de agencias de fomento.

${ }^{5}$ Este salário é diferenciado dos demais TILS de Maracanaú, posto que o vínculo estabelecido está configurado em regime de estágio, sendo o profissional aluno em processo de graduação na área da Licenciatura em Educação Física.

${ }^{6}$ A diferença entre a média salarial dos TILS de Maracanaú ocorre em função da diferença de carga horária - menor salário (100h) e maior salário (200h).

${ }^{7} \mathrm{SM}$ = Salário Mínimo

${ }^{8}$ Cabe destacar que nosso argumento tem como foco não apenas o grupo de sujeitos da pesquisa, que, aliás, tem níveis de formação diferenciados. É preciso refletir sobre a questão como um todo - como uma situação a ocorrer em diversos lugares, e que os TILS contratados poderão ter uma licenciatura ou não.

\section{Correspondência}

Adriane Melo de Castro Menezes - Universidade Federal de Roraima, CCLA_Cenro De Comunicação Letras e Artes (Curso Letras-Libras Bacharelado). AC UFRR - Aeroporto. CEP: 69310970 - Boa Vista, Roraima, Brasil.

E-mail:drimcmenezes@gmail.com - cristinalacerda@uol.com.br

Recebido em 28 de maio de 2016

Aprovado em 20 de janeiro de 2017 